\title{
ALTERNATIF TEKNIK KONSERVASI TANAH DAN AIR UNTUK DAS CILEMER,
} BANTEN

\section{Alternative of Soil and Water Conservation Techniques in Cilemer Watershed, Banten}

\author{
Evi Nursari1)*, Latief Mahir Rachman²) dan Dwi Putro Tejo Baskoro²) \\ 1) Program Studi Ilmu Pengelolaan Daerah Aliran Sungai (DAS), Sekolah Pascasarjana, Institut Pertanian Bogor, \\ Kampus IPB Darmaga, Bogor, 16680 \\ 2) Departemen Ilmu Tanah dan Sumberdaya Lahan, Fakultas Pertanian IPB, Institut Pertanian Bogor, J1. Meranti \\ Kampus IPB Dramaga, Bogor 16680
}

\begin{abstract}
Floods and droughts are routine problems that occur in Cilemer Watershed due to their decrease in quality. Application of Soil and Water Conservation (SWC) is one solution to improve the quality of Cilemer Watershed. A study aimed to simulate several SWC, obtain alternative of SWC and provides the best watershed management directions was carried out Cilemer Watershed. The research was carried out in several stages: (i) secondary data collection, (ii) field survey (primary data collection), (iii) data analysis, (iv) running SWAT model, (v) SWC simulation with SWAT model, (vi) watershed management scenarios, and (vii) arrangement of watershed management directives. The result shows that the application of SWC can improve watershed quality which is characterized by decreases $Q_{\max } / Q_{\min }$ ratio and direct runoff but increases base flow and water yield. Application of mini traditional reservoir is the best watershed management scenario. This scenario is able to decrease the direct runoff, but increase base flow and water yield much greater than other scenarios. Application of mini traditional reservoir decreses direct runoff by $29.24 \%$, where the coefficient of runoff decreases from 0.25 (existing condition) to 0.17. In addition, the scenario can also increase base flow by $46.00 \%$ (from $357.5 \mathrm{~mm}$ to $522.0 \mathrm{~mm}$ ) and water yield by $3.99 \%$. Water yield increase from $904.5 \mathrm{~mm}$ (existing condition) to $941.0 \mathrm{~mm}$.
\end{abstract}

Keywords: Agroforestry, mini dam, strip cropping, SWAT model

\begin{abstract}
ABSTRAK
Banjir dan kekeringan merupakan persoalan rutin yang terjadi di Daerah Aliran Sungai (DAS) Cilemer karena kualitasnya menurun. Penerapan Konservasi Tanah dan Air (KTA) merupakan salah satu upaya untuk meningkatkan kualitas DAS Cilemer. Studi ini bertujuan untuk mensimulasikan beberapa teknik KTA, mendapatkan alternatif teknologi KTA, dan menyusun arahan pengelolaan DAS yang baik. Penelitian dilaksanakan kedalam beberapa tahap yaitu: (i) pengumpulan data sekunder, (ii) survei lapang (pengumpulan data primer), (iii) analisis data, (iv) running model SWAT, (v) simulasi KTA dengan model SWAT, (vi) skenario pengelolaan DAS, serta (vii) penyusunan arahan pengelolaan DAS. Hasil penelitian menunjukkan bahwa penerapan KTA dapat memperbaiki kualitas DAS yang ditandai dengan menurunnya rasio $\mathrm{Q}_{\max } / \mathrm{Q}_{\min }$ dan aliran permukaan langsung serta meningkatnya aliran dasar dan water yield. Strip cropping, agroforestry dan embung dapat dijadikan alternatif teknologi KTA yang dapat diimplementasikan secara simultan di DAS Cilemer pada sub agroekosistem dimana teknologi tersebut sesuai untuk diterapkan. Embung adalah skenario pengelolaan DAS terbaik, yang mampu menurunkan aliran permukaan langsung sebesar 29.24\%, koefisien aliran tahunan menurun dari 0.25 menjadi 0.17 , meningkatkan aliran dasar sebesar $46.00 \%$ dan hasil air sebesar $3.99 \%$.
\end{abstract}

Kata kunci: Agroforestry, embung, strip cropping, model SWAT

\section{PENDAHULUAN}

Peningkatan jumlah penduduk yang terus terjadi namun luas lahan tidak berubah (tetap) mengakibatkan meningkatnya kebutuhan akan lahan sehingga memicu peningkatan laju alih fungsi lahan. Alih fungsi lahan serta praktek pertanian yang tidak mengindahkan kaidah konservasi tanah dan air menjadi salah satu penyebab menurunnya fungsi hidrologi Daerah Aliran Sungai (DAS). Penurunan fungsi hidrologi DAS ditandai dengan ketidakmampuan DAS dalam meredam lonjakan fluktuasi aliran permukaan yang diakibatkan oleh turunnya hujan serta tidak mampu menstabilkan ketersediaan air pada musim kemarau (Djuwansah, 2006). Diperparah lagi dengan adanya curah hujan yang sangat ekstrim akibat perubahan iklim sehingga menambah memperburuk kondisi hidrologi DAS.

Banjir merupakan persoalan rutin yang sering terjadi tiap tahunnya di beberapa wilayah kabupaten yang ada di Banten terutama apabila hujan ekstrim mengguyur cukup lama, yang salah satunya adalah daerah yang dilintasi oleh Sungai Cilemer. Wilayah DAS Cilemer merupakan dataran rendah yang rawan akan terjadinya banjir. Menurut hasil kajian Dinas PUPR (2015), sebesar 77.38 \% wilayah DAS Cilemer adalah dataran rendah dengan ketinggian 0-25 m. Menurut Slamet dan Sarwono (2016) penyebab banjir pada S. Cilemer adalah perbedaan kapasitas sungai pada bagian hulu dan hilir serta penambahan debit banjir dari anak - anak sungai. Selain hal itu 
kemiringan dasar sungai yang sangat landai menyebabkan kecepatan aliran menjadi kecil.

Terjadinya banjir di DAS Cilemer tentunya akan berdampak pada ketersediaan air, jika kelebihan air tersebut tidak terserapkan kedalam tanah. DAS Cilemer merupakan salah satu DAS di Provinsi Banten yang memiliki fungsi sebagai sumber irigasi pertanian di Provinsi Banten khususnya untuk wilayah Banten Selatan terutama Kabupaten Pandeglang. Mengingat sebagian besar penggunaan lahan di DAS Cilemer adalah sawah dan pertanian lahan kering maka pasokan irigasi sangat diperlukan dalam hal ini. Disamping itu, dalam Rencana Tata Ruang Wilayah Provinsi Banten Tahun 2010-2030 Pemprov Banten (2011) mengalokasikan adanya Daerah Irigasi Cilemer di Kabupaten Pandeglang, seluas 2,672 ha. Oleh sebab itu, keberadaan DAS Cilemer cukup penting bagi sektor pertanian Banten sehingga fungsi dan kondisinyaperlu dijaga.

Upaya peningkatan fungsi hidrologi DAS Cilemer perlu dilakukan agar permasalahan banjir dan kekeringan yang merugikan masyarakat Banten terutama sektor pertanianya dapat dikendalikan, yaitu salah satunya dengan melakukan pengelolaan DAS. Pengelolaan DAS adalah upaya manusia dalam mengatur hubungan timbal balik antara sumberdaya alam dengan manusia di dalam DAS dan segala aktivitasnya, agar terwujud kelestarian dan keserasian ekosistem serta meningkatnya kemanfaatan sumberdaya alam bagi manusia secara berkelanjutan (PP Nomor 37, 2012). Salah satu upaya pengelolaan DAS yaitu dengan penerapan Konservasi Tanah dan Air (KTA). Konservasi tanah merupakan penempatan sebidang tanah sesuai dengan kemampuanya dan syarat-syarat yang diperlukan agar tidak terjadi degradasi lahan. Sementara konservasi air adalah upaya untuk mengawetkan air di dalam tanah, dimana pada saat hujan,air diusahakan masuk ke dalam tanah dan ditahan di dalam tanah sehingga bisa dimanfaatkan pada saat musim kemarau (Arsyad, 2006; Arsyad, 2010).

Berbagai metode KTA baik berupa metode vegetatif, kimia, maupun mekanik dalam upaya pengelolaan DAS sudah banyak dikembangkan. Studi yang dilakukan di Sumba Timur menunjukkan bahwa praktek konservasi tanah dan air dengan penanaman rumput tertentu mampu memperbaiki sifat fisik dan kimia tanah pada daerah yang didominasi savana dengan sistem peternakan lepas (Rachmawati, 2012). Menurut Kustamar (2013) perpaduan antara metode vegetative, kimia dan mekanik pada umumnya sangat efektif dalam mengendalikan banjir. Oleh sebab itu, dalam penelitian ini dilakukan simulasi teknik KTA sebagai upaya pengelolaan DAS guna mencari pengelolaan DAS terbaik yang dapat diterapkan di DAS Cilemer.

Tujuan dari penelitian ini adalah: (i) mensimulasikan beberapa teknik KTA sebagai upaya pengendalian banjir dan peningkatan pasokan air irigasi pertanian DAS Cilemer; (ii) mendapatkan alternatif teknologi KTA untuk pengelolaan DAS Cilemer, dan (iii) menyusun arahan pengelolaan DAS yang baik untuk meningkatkan fungsi hidrologi DAS Cilemer.

\section{BAHAN DAN METODE}

\section{Tempat dan Waktu Penelitian}

Penelitian dilaksanakan selama 8 bulan dari bulan Januari hingga Agustus 2017. Lokasi Penelitian terletak di DAS Cilemer yang secara geografis terletak pada $105^{\circ} 48^{\prime} 25^{\prime}$ $106^{\circ} 05^{\prime} 05^{\prime}$ " BT serta $6^{\circ} 16^{\prime} 58^{\prime \prime}-6^{\circ} 35^{\prime} 13^{\prime \prime} \mathrm{LS}$. DAS Cilemer termasuk kedalam wilayah administrasi Kabupaten Pandeglang dan Lebak, Provinsi Banten (Gambar 1). Pengolahan data dan analisis tanah dilakukan di Laboratorium Departemen Ilmu Tanah dan Sumberdaya Lahan, Kampus IPB Dramaga, Bogor.

\section{Alat dan Bahan}

Alat yang digunakan dalam penelitian adalah seperangkat komputer, Software ArcGIS 10.1, ArcSWAT versi 10.1.18, Microsoft Office 2010, Global Positioning System (GPS), ring sampler, double ring infiltrometer dan alat-alat lainnya yang diperlukan untuk pengambilan sampel fisik tanah dan analisis di laboratorium. Adapun bahan yang akan digunakan dalam penelitian ini terdiri dari data spasial dan numerik yaitu: (i) Peta DEM (Digital Elevation Model) Banten yang diturunkan dari citra SRTM resolusi $30 \mathrm{~m}$ (sumber download dari CGIAR-CSI), (ii) Peta tutupan lahan DAS Cilemer skala 1:250,000 (Dinas PUPR Banten, 2015), (iii) Peta Tanah DAS Cilemer skala 1:250,000 (Balai Besar Penelitian dan Pengembangan Sumberdaya Lahan Pertanian), (iv) Data Iklim tahun 20102015 (sumber dari BMKG kota Serang) diantaranya: curah hujan harian $(\mathrm{mm})$, temperatur maksimum dan minimum harian $\left({ }^{\circ} \mathrm{C}\right)$, data kelembaban udara harian $(\%)$, data radiasi matahari harian $\left(\mathrm{MJ} \mathrm{m} \mathrm{m}^{-2}\right.$ hari $\left.^{-1}\right)$, data kecepatan angin harian $\left(\mathrm{m} \mathrm{s}^{-1}\right)$, (v) Data debit observasi harian Sungai Cilemer tahun 2010-2015 (sumber dari Balai PSDA WS Ciliman-Cisawarna), dan (vi) Data karakteristik fisik tanah DAS Cilemer (pengamatan lapang).

\section{Metode Penelitian}

Penelitian dilakukan kedalam 7 (tujuh) tahap yaitu: (i) pengumpulan data sekunder, (ii) survei lapang (pengumpulan data primer), (iii) analisis data, (iv) running model Soil Water Assesment Tool (SWAT), (v) simulasi KTA dengan model SWAT, (vi) skenario pengelolaan DAS, serta (vii) penyusunan arahan pengelolaan DAS.

\section{Pengumpulan Data Sekunder}

Data sekunder diperoleh dari lembaga atau instansi terkait serta diunduh dari internet.

\section{Survei Lapang (Pengumpulan Data Primer)}

Survei lapang ditujukan untuk pengamatan parameter di lapangan dan pengambilan sampel tanah yang nantinya diujikan di laboratorium.

\section{Analisa Data}

Data yang terkumpul dianalisa guna menggambarkan kondisi hidrologi dan untuk mensimulasikan teknik konservasi tanah dan air di DAS Cilemer.

\section{Running Model SWAT}

Simulasi KTA dilakukan dengan bantuan model SWAT. Model SWAT merupakan alat yang dapat digunakan untuk mengidentifikasi, menilai dan mengevaluasi kondisi hidrologi DAS sehingga dapat ditetapkan tindakan pengelolaan DAS yang tepat dan sesuai (Junaidi dan Tarigan, 2012). Sebelum digunakan untuk simulasi KTA, hasil model SWAT perlu dilakukan proses kalibrasi dan validasi. 


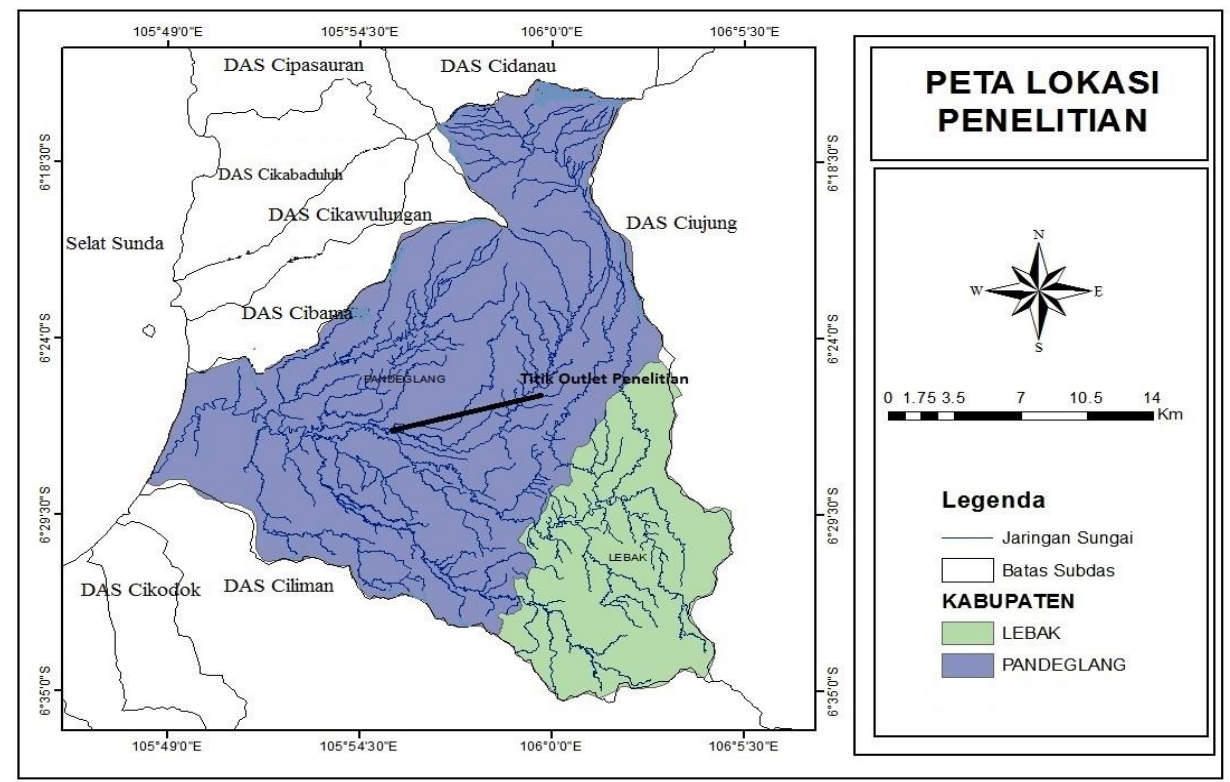

Gambar 1. Lokasi penelitian (DAS Cilemer)

Proses kalibrasi dilakukan untuk mencari parameter model yang sesuai agar hasil simulasi mendekati dengan hasil yang sebenarnya dilapangan. Pada penelitian ini, kalibrasi dilakukan secara manual yakni pemilihan nilai parameter dilakukan secara coba-coba (trial and error) sampai menemukan nilai parameter yang cocok sehingga menghasilkan nilai NSE (Nash-Sutclife Efficiency) yang memuaskan. Santhi et al. (2001) mengusulkan pendekatan kalibrasi manual dimana berdasarkan hasil penelitiannya didapatkan 15 fungsi parameter yang sensitif dengan rentang ketidakpastian yang realistis dan hasil $\mathrm{R}^{2}$ dan NSE yang memuaskan.

Proses kalibrasi dalam penelitian ini menggunakan data debit aliran tahun 2013 dari hasil pengamatan Stasiun Pengamatan Aliran Sungai (SPAS) Kadubera di DAS Cilemer. Adapun parameter yang digunakan dalam penelitian ini terdiri dari 15 parameter yaitu $\mathrm{CHK} 2, \mathrm{CHN} 2, \mathrm{GW}$ DELAY, GW_QMIN, ALPHA_BF, ESCO, EPCO, CN2, REVAPMN, RCHRG_DP, OV_N, GW_REVAP, SHALLST

Validasi merupakan proses pengujian konsistensi model dengan menggunakan parameter yang sama seperti pada proses kalibrasi. Validasi dalam penelitian ini menggunakan data debit harian tahun 2015.

Uji kalibrasi dan validasi dihitung berdasarkan persamaan NSE dan koefisien determniasi $\left(\mathrm{R}^{2}\right)$ dengan membandingkan data debit harian simulasi dan data debit harian observasi.

$$
N S E=1-\frac{\sum_{i=1}^{n}\left(Q_{M i}-Q_{S i}\right)^{2}}{\sum_{i=1}^{n}\left(Q_{M}-Q_{S i}\right)^{2}} \text { dan } R^{2}=\frac{(O-\overline{0})^{2}-(O-P)^{2}}{(O-\overline{0})^{2}}
$$

Keterangan: $\mathrm{QSi}=$ nilai simulasi model, $\mathrm{QMi}=$ nilai observasi, $\mathrm{QM}=$ rata-rata nilai observasi, $\mathrm{n}=$ jumlah data, $\mathrm{O}$ $=$ data observasi, $\overline{\mathrm{O}}=$ data observasi rata-rata, dan $\mathrm{P}=$ data simulasi.

Kisaran nilai NSE dan $\mathrm{R}^{2}$ adalah 0 sampai 1 , jika nilai NSE dan $\mathrm{R}^{2}$ semakin mendekati angka 1 maka performa model dapat dikatakan optimal dimana hasil simulasi mendekati hasil pengukuran di lapangan. Tingkat performa model berdasarkan NSE ditunjukan pada Tabel 1.

Tabel 1. Tingkat performa model berdasarkan NSE

\begin{tabular}{lc}
\hline \multicolumn{1}{c}{ Tingkat Performa } & NSE \\
\hline Sangat baik & $>0.75$ \\
Baik & $0.65-0.75$ \\
Memuaskan & $0.50-0.65$ \\
Tidak memuaskan & $\leq 0.50$ \\
\hline Sumber: Moriasi et al. (2007)
\end{tabular}

\section{Skenario Pengelolaan DAS}

Setelah hasil model SWAT bisa digunakan maka selanjutnya dilakukan simulasi KTA dengan menerapkan beberapa skenario. Adapun teknik KTA yang diusulkan dalam penelitian ini adalah:

- Skenario 1: KTA dengan strip cropping. Strip cropping adalah sistem bercocok tanam dengan beberapa jenis tanaman yang ditanam dalam strip berselang seling dalam sebidang tanah dan disusun memotong lereng (Arsyad, 2010). Sistem KTA ini memiliki keunggulan yakni dari segi biaya penerapannya cukup murah.

Tabel 2. Skenario pengelolaan DAS Cilemer

\begin{tabular}{|c|c|c|c|c|}
\hline Metode KTA & Simulasi Parameter Hidrologi & Nomor Sub DAS & Luas (ha) & $\%$ \\
\hline Strip cropping & STRIP_CN, STRIP_P, dan STRIP_C & $1,2,5-24$ & 13,852 & 49.44 \\
\hline Agroforestri & SOL_BD, SOL_C, SOL AWC, dan CN2 & $1,2,5-10,12-18,20-24$ & 1,999 & 7.14 \\
\hline Embung & PND_SA, PND_VOL, dan CN2 & $1,2,5-10,12-24$ & 10,913 & 38.95 \\
\hline
\end{tabular}


- Skenario 2: KTA dengan sistem agroforestri. Agroforestri adalah sistem penggunaan lahan yang mengkombinasikan pepohonan dengan tanaman pertanian untuk meningkatkan keuntungan secara ekonomi dan lingkungan (Ruijter dan Agus, 2004). Banyaknya keuntungan yang didapatkan dari penerapan KTA ini sehingga sistem KTA ini layak untuk diunggulkan.

- Skenario 3: KTA dengan pembuatan embung. Embung adalah kolam yang berfungsi menampung air saat musim hujan sehingga air tersebut dapat digunakan untuk musim kemarau (Balitbang Pertanian, 2017).

\section{Penyusunan Arahan Pengelolaan DAS}

Arahan pengelolaan DAS disusun berdasarkann hasil simulasi beberapa skenario KTA. Skenario KTA terbaik yang dipilih untuk direkomendasikan untuk pengelolaan DAS adalah berdasarkan kriteria kemampuannya dalam menurunkan Koefisien Regim Aliran (KRA) dan Koefisien Aliran Tahunan (KAT), serta meningkatkan aliran dasar dan water yield paling tinggi. Namun, apabila dalam kasus ditemukan hasil skenario terbaik berbeda untuk masing-masing kriteria, maka skenario terbaik dipilih berdasarkan yang paling banyak masuk ke dalam kriteria.

Adapun untuk menghitung nilai KRA dan KAT adalah sebagai berikut:

a. KRA

$$
K R A=\frac{Q \max }{Q \min }
$$

Kriteria kualitas DAS berdasarkan KRA ditunjukan pada Tabel 3 .
Tabel 3. Kriteria kualitas DAS berdasarkan nilai KRA

\begin{tabular}{lcc}
\hline Kategori & KRA & Klasifikasi DAS \\
\hline Sangat Rendah & $\leq 20$ & Sangat baik \\
Rendah & $20-50$ & Baik \\
Sedang & $50-80$ & Sedang \\
Tinggi & $80-110$ & Buruk \\
Sangat Tinggi & $>110$ & Sangat Buruk \\
\hline \multicolumn{2}{l}{ Sumber: Dirjen RLPS dalam Permenhut, 2014 }
\end{tabular}

\section{b. KAT}

$$
C=\frac{\text { Direct Runoff }(\mathrm{mm})}{\text { Curah Hujan }(\mathrm{mm})}
$$

Kriteria kualitas DAS berdasarkan KAT ditunjukan pada Tabel 4.

Tabel 4. Kriteria kualitas DAS berdasarkan nilai KAT

\begin{tabular}{lc}
\hline Kategori & KAT \\
\hline Sangat Rendah & $\leq 0.2$ \\
Rendah & $0.2-0.3$ \\
Sedang & $0.3-0.4$ \\
Tinggi & $0.4-0.5$ \\
Sangat Tinggi & $>0.5$ \\
\hline Sumber: Dirjen RLPS dalam Permenhut, 2014 &
\end{tabular}

\section{HASIL DAN PEMBAHASAN}

\section{Kalibrasi dan Validasi Model SWAT}

Hasil kalibrasi model SWAT didapatkan bahwa nilai $\mathrm{R}^{2}$ dan NSE masing-masing adalah 0.65 dan 0.63. Berdasarkan kategori tingkat performa model menurut Moriasi et al. (2007) model tersebut dapat dikatakan memuaskan karena $>0.5$ (Gambar 2). Sementara untuk validasi yang dilakukan pada tahun 2015 menghasilkan $\mathrm{R}^{2}$ dan NSE masing-masing adalah 0.57 dan 0.52 dikategorikan memuaskan (Gambar 3).

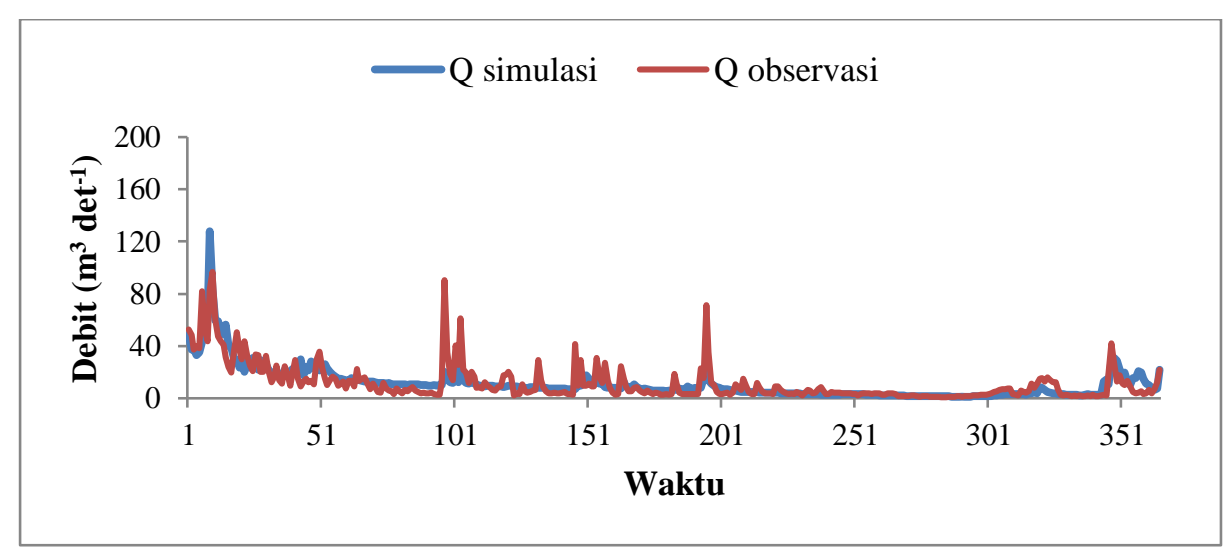

Gambar 2. Hasil kalibrasi model SWAT DAS Cilemer (tahun 2013) 


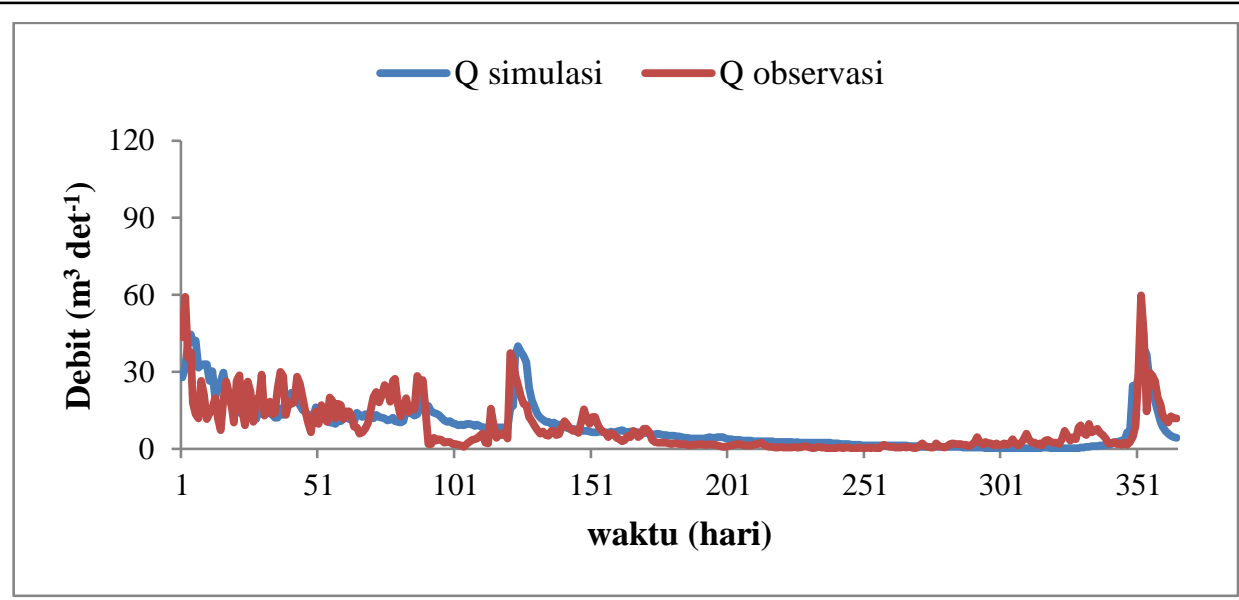

Gambar 3. Hasil validasi model SWAT DAS Cilemer (tahun 2015)

Kalibrasi dan validasi model merupakan faktor kunci dalam mengurangi ketidakpastian dan peningkatan kepercayaan pengguna terhadap kemampuan prediksinya, yang mana membuat aplikasi model menjadi efektif (White dan Chaubey, 2005). Kalibrasi dan validasi juga dapat dijadikan sebagai ukuran kehandalan simulasi dalam suatu model, kehandalan simulasi model dipengaruhi oleh lama panjangnya periode simulasi serta kualitas data pengukuran yang digunakan (keakuratanya) (Saleh et al., 2009). Setelah dilakukan kalibrasi dan validasi pada model, maka dengan begitu model dapat digunakan untuk simulasi skenario untuk menghasilkan arahan pengelolaan suatu DAS.

\section{Simulasi Teknik Konservasi Tanah dan Air dengan Model SWAT}

Hasil simulasi skenario KTA menggunakan model SWAT menunjukan bahwa penerapan teknik KTA mampu menurunkan KRA, dapat dilihat dari nilai KRA pada masing-masing skenario lebih rendah dari nilai KRA kondisi eksisiting (Tabel 5). Skenario 1 yang merupakan KTA dengan metode strip cropping mampu menurunkan KRA sebesar 22.39\% (dari 119.70 menjadi 92.89), skenario 2 (KTA metode agroforestri) mampu menurunkan KRA sebesar 9.83\% (dari 229.70 menjadi 107.93\%), dan skenario 3 (KTA metode embung) mampu menurunkan KRA sebesar 21.26\% (dari 119.70 menjadi 94.25).

Pengaruh skenario KTA terhadap aliran permukaan, aliran dasar dan water yield dapat dilihat pada Tabel 6. Adanya penerapan KTA dapat menekan aliran permukaan dan meningkatkan aliran dasar dan water yield.
Skenario 1 mampu menurunkan aliran permukaan langsung (Direct Runoff) sebesar 28.93\% (KAT menurun dari 0.25 menjadi 0.18 ) serta meningkatkan aliran dasar dan water yield masing-masing sebesar $40.56 \%$ dan $2.06 \%$. Penerapan KTA strip cropping pada skenario 1 menyebabkan permukaan tanah terlindungi dari pukulan air hujan sehingga struktur tanah terjaga. Air hujan yang jatuh akan lebih banyak terinfiltrasi sehingga aliran permukaan hanya sedikit, dan yang menjadi aliran dasar lebih banyak.

Skenario 2 mampu menurunkan aliran permukaan langsung sebesar $8.87 \%$ sehingga nilai KAT menurun dar 0.25 menjadi 0.22 , serta meningkatkan aliran dasar dan water yield masing-masing sebesar $13.12 \%$ dan $0.89 \%$. Naungan yang berasal dari pola agroforestri dapat memaksimalkan perlindungan tanah dari pukulan air hujan. Disamping itu, keberadaan serasah hasil dari sisasisa tanaman pohon dapat memperbaiki sifat fisik tanah terutama struktur tanahnya sehingga kemampuan infiltrasinya meningkat kemudian aliran permukaan akan berkurang dan aliran dasar akan meningkat.

Skenario 3 mampu menurunkan aliran permukaan langsung sebesar $29.24 \%$ sehingga nilai KAT menurun dari 0.25 menjadi 0.17 , serta meningkatkan aliran dasar dan water yield masing-masing sebesar $46.00 \%$ dan $3.99 \%$. Penerapan embung dalam skenario 3 dapat menekan aliran permukaan pada musim penghujan, selain itu juga embung dapat berfungsi untuk mengalirkan air hasil tampungan pada musim penghujan ke saluran baik saluran sungai maupun irigasi ketika musim kemarau.

Tabel 5. Nilai KRA hasil simulasi berbagai skenario KTA

\begin{tabular}{lcccrr}
\hline Skenario & Rata-rata $\left(\mathrm{m}^{3} \mathrm{dt}^{-1}\right)$ & Qmax $\left(\mathrm{m}^{3} \mathrm{dt}^{-1}\right)$ & Qmin $\left(\mathrm{m}^{3} \mathrm{dt}^{-1}\right)$ & \multicolumn{1}{c}{ KRA } & \% Perubahan \\
\hline Eksisting & 8.41 & 41.08 & 0.34 & 119.70 & \\
Skenario 1 & 8.61 & 39.20 & 0.42 & 92.89 & -22.39 \\
Skenario 2 & 8.49 & 39.59 & 0.37 & 107.93 & -9.83 \\
Skenario 3 & 8.68 & 39.15 & 0.42 & 94.25 & -21.26 \\
\hline
\end{tabular}

Tabel 6. Nilai KAT, aliran dasar, dan water yield pada berbagai skenario KTA

\begin{tabular}{cccccccc}
\hline Skenario & $\begin{array}{c}\text { Curah Hujan } \\
(\mathrm{mm})\end{array}$ & $\begin{array}{c}\text { DRO* } \\
(\mathrm{mm})\end{array}$ & KAT & $\begin{array}{c}\text { Perubahan DRO } \\
(\%)\end{array}$ & $\begin{array}{c}\text { Aliran dasar } \\
(\mathrm{mm})\end{array}$ & $\begin{array}{c}\text { Water Yield } \\
(\mathrm{mm})\end{array}$ & $\begin{array}{c}\text { Perubahan Water Yield } \\
(\%)\end{array}$ \\
\hline Eksisting & $1,972.6$ & 486.0 & 0.25 & & 357.5 & 904.5 & +2.06 \\
Skenario 1 & $1,972.7$ & 345.4 & 0.18 & -28.93 & 502.6 & 923.2 & +0.89 \\
Skenario 2 & $1,972.7$ & 442.9 & 0.22 & -8.87 & 404.5 & 912.8 & +3.99 \\
Skenario 3 & $1,972.7$ & 343.9 & 0.17 & -29.24 & 522.0 & 941.0 & \\
*DRO $=$ Direct Runoff & & & & & &
\end{tabular}




\section{Arahan Pengelolaan DAS Cilemer}

Hasil simulasi KTA pada berbagai skenario di DAS Cilemer diketahui dapat menurunkan KRA, KAT serta meningkatkan aliran dasar dan water yield. Namun, dalam memilih arahan pengelolaan DAS terbaik diarahkan pada pengelolaan DAS yang mampu menurunkan KRA, KAT serta meningkatkan aliran dasar dan water yield paling tinggi.

Dilihat dari nilai KRA (Gambar 4), skenario 1 yang merupakan penerapan metode strip cropping dianggap merupakan skenario paling baik dari dua skenario lainnya. Skenario strip cropping mampu meningkatkan fungsi hidrologi DAS dari kategori sangat buruk menjadi sedang dengan presentasi penurunan KRA sebesar $22.39 \%$, akan tetapi pada skenario embung juga tidak berbeda jauh dengan skenario strip cropping, dimana presentasi penurunan KRA sebesar $21.26 \%$.

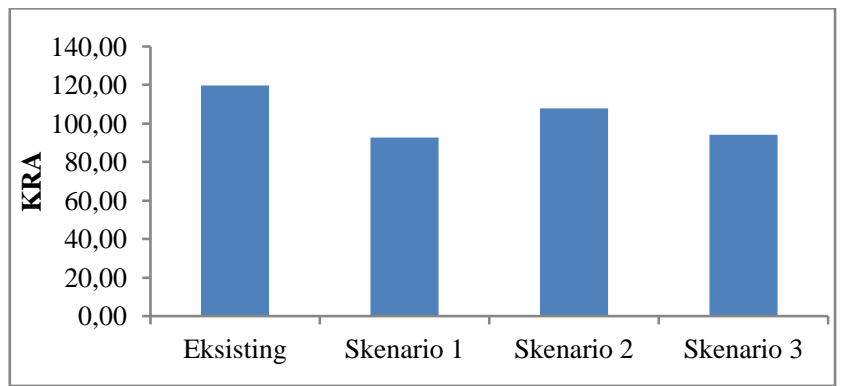

Gambar 4. Hasil KRA pada berbagai skenario KTA

Dilihat dari nilai aliran permukaan, aliran dasar dan water yield, masing-masing skenario mengalami penurunan aliran permukaan serta peningkatan aliran dasar dan water yield. Namun, dari ke 3 skenario, skenario embung memiliki proporsi penurunan aliran permukaan paling besar. Skenario tersebut mampu menekan aliran permukaan sebesar $29.24 \%$ sehingga nilai KAT menurun dari 0.25 (kondisi eksisting) menjadi 0.17. Disamping menekan aliran permukaan, skenario embung juga dapat meningkatkan aliran dasar sebesar $46.00 \%$ dan water yield sebesar $3.99 \%$. Aliran dasar dan water yield dapat dijadikan tolak ukur dalam meningkatkan ketersediaan air terutama pada musim kemaru, sehingga dengan meningkatnya aliran dasar dan water yield pada skenario embung, maka dapat dikatakan skenario embung lebih baik dalam meningkatkan ketersediaan air dibandingkan skenario lainnya.

Secara keseluruhan dari ketiga skenario KTA yang disimulasikan di DAS Cilemer (Gambar 5), skenario 3 dianggap skenario paling baik karena paling banyak masuk ke dalam kriteria pengelolaan DAS terbaik yakni dapat menurunkan KTA, serta meningkatkan aliran dasar dan water yield paling tinggi. Perubahan respon hidrologi DAS Cilemer ke arah yang lebih baik pada skenario 3 dikarena penerapan KTA embung sebagai wadah yang dapat menampung aliran permukaan yang datang dari areal lahan di bagian hulu sehingga dapat menekan aliran permukaan di DAS Cilemer. Embung juga dapat digunakan untuk memenuhi kebutuhan air tanaman selama musim kemarau yang ditetapkan dengan mempertimbangkan ketersediaan air dalam embung (Rejekiningrum dan Haryati, 2002).

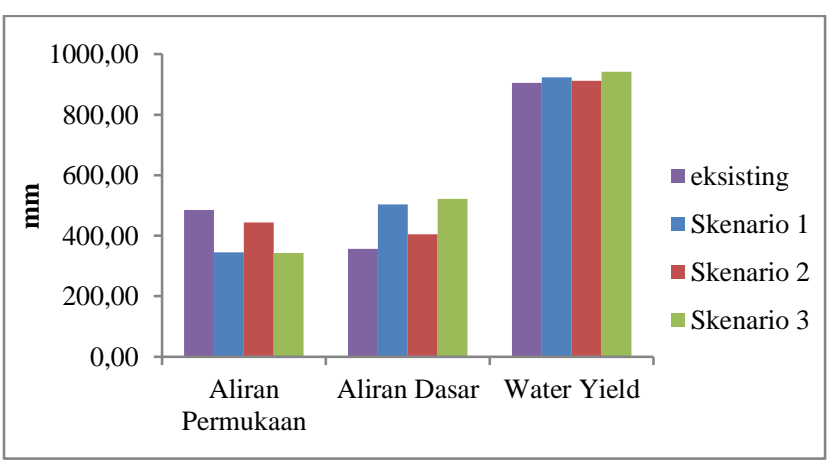

Gambar 5. Aliran permukaan, aliran dasar dan water yield pada berbagai skenario KTA

\section{SIMPULAN}

Semua skenario Konservasi Tanah dan Air (strip cropping, agroforestri dan embung) yang disimulasikan di DAS Cilemer dapat menurunkan KRA dan KTA serta meningkatkan aliran dasar dan water yield.

Strip cropping, agroforestri dan embung dapat dijadikan alternatif teknologi KTA yang dapat diimplementasikan secara simultan di DAS Cilemer pada sub agroekosistem dimana teknologi tersebut sesuai untuk diterapkan.

Teknik pengelolaan DAS yang diarahkan untuk diterapkan di DAS Cilemer dalam rangka pengendalian banjir dan peningkatan ketersediaan air adalah embung dengan total volume tampungan sebesar $300 \mathrm{~m}^{3}$ karena mampu menurunkan aliran permukaan, meningkatkan aliran dasar dan water yield yang lebih baik dari skenario lainnya.

\section{DAFTAR PUSTAKA}

Arsyad, S. 2006. Konservasi Tanah dan Air. Institut Pertanian Bogor Press, Bogor.

[Balitbang Pertanian] Balai Penelitian dan Pengembangan Pertanian. 2017. Teknologi Embung. http:// litbang.pertanian.go.id/tahukah-anda/156/ (diakses pada 10 Januari 2018).

[Dinas PUPR] Dinas Pekerjaan Umum dan Perumahan Rakyat Banten. 2015. Kajian evaluasi kinerja penyelesaian pengendalian banjir DAS Cilemer. Laporan Akhir. Dinas PUPR. Banten.

[Ditjen RLPS] Direktorat Jenderal Rehabilitasi Lahan dan Perhutanan Sosial. 2014. Peraturan Direktur Jenderal Rehabilitasi Lahan dan Perhutanan Sosial Nomor: P. 61 /Menhut-II/2014 tentang Pedoman Monitoring dan Evaluasi Daerah Aliran Sungai. Jakarta.

Djuwansah, M.R. 2006. Teknologi Indonesia. LIPI Press. Volume 29, No.2, Jakarta

Junaidi, E. dan S.D. Tarigan. 2012. Penggunaan model hidrologi SWAT (Soil and Water Assessment Tool) dalam pengelolaan DAS Cisadane. Jurnal Penelitian Hutan dan Konservasi Alam, 9:221237. 
Kustamar. 2013. Strategi pengendalian banjir berbasis konservasi sumber daya air di DAS Sungai Nangka, Lombok Timur. Konferensi Nasional Teknik Sipil 7, Surakarta 24-26 Oktober.

Moriasi, D.N., J.G. Arnold, M.W. Van Liew, R.L. Bingner, R.D. Harmel and T.L. Veith. 2007. Model evaluation guidelines for systematic quantification of accuracy in watershed simulation. American Society of Agricultural and Biological Engineers, 50:885-900.

[Pemprov Banten] Pemerintah Provinsi Banten. 2011. Peraturan Daerah No. 2 tentang Rencana Tata Ruang Wilayah Provinsi Banten Tahun 2010-2030. Pemerintah Provinsi Banten, Banten.

[PP] Peraturan Pemerintah Nomor 37 Tahun 2012. 2012. Pengelolaan Daerah Aliran Sungai. Kementerian Sekretariat Negara Republik Indonesia.

Rachmawati, I. 2012. Konservasi Tanah dan Air Secara Partisipatif dengan Pendekatan Agroforestri Lokal. Prosiding Semiloka. Surakarta: 27-28 Juni 2011.

Rejekiningrum, P. dan U. Haryati. 2002. Panen hujan dan aliran permukaan untuk meningkatkan produktivitas lahan kering di Nyatnyono, DAS Kaligarang, Semarang. J. Agromet., 1:61-75.

Ruijter, J. and F. Agus. 2004. Pengelolaan Daerah Aliran Sungai (DAS). World Agroforestry Center, Bogor.

Saleh, D.K., C.R. Kratzer, C.H. Green and D.G. Evans. 2009. Using the Soil and Water Assesment Tool (SWAT) to simulate runoff in Mustang Creek Basin, California. Scientific Investigation Report. US Department of Interior.

Santhi, C., J.G. Arnold, J.R. Williams, W.A. Dugas, R. Srinivasan and L.M. Hauck. 2001. Validation of the SWAT model on a large river basin with point and nonpoint sources. J. American Water Resour. Assoc., 37:1169-1188.

Slamet, N.S. dan Sarwono. 2016. Simulasi genangan banjir menggunakan data ASTER DEM pada aliran Sungai Cilemer. J. Sumber Daya Air, 12:61-67.

White, K.L. and I. Chaubey. 2005. Sensitivity analysis, calibration, and validation for a multisite and multivariable SWAT Model 1. JAWRA Journal of the American Water Resources Association, 41:1077-1089. 